\title{
Campylobacter infection in broiler breeder flocks in El-Minia governorate
}

\author{
A. M. Youssif \\ Department of Bacteriology, Animal Health Research Institute, El-Minia Branch, El-Minia, Egypt.
}

\begin{abstract}
Existence of Campylobacter species that colonize broiler chickens intestinal tract raised and slaughtered in El-Minia Governorate as a source of animal protein origin for human consumption were studied. Samples were collected from 381 broiler chickens from different private farms distributed in six cities related to El-Minia Governorate and examined for the prevalence of Campylobacter spp. Percentage of Campylobacter jejuni isolation was $19.5 \%, 14.8 \%, 18.3 \%$, $14.7 \%, 12.3 \%$ and $12.1 \%$ from Maggagha, Beni-Mazar, Samalout, Abou-Curcas, Mallawey and Deer-Mouase, respectively. While Campylobacter coli was $4.8 \%, 6.2 \%, 4.3 \%, 6.7 \%, 3.5 \%$ and $\mathbf{0 . 0 \%}$ respectively . Higher rate of isolation of Campylobacter jejuni $18.0 \%$ and Campylobacter coli $5.1 \%$ were obtained from 216 freshly dead broiler chickens carcasses than 165 diseased and slaughter birds which revealed $13.3 \%$ and $4.2 \%$, respectively . Overall, Campylobacter spp. showed a higher tissue affinity for caecum (11.3\%) Campylobacter jejuni and (2.6\%) Campylobacter coli than for jejunum (4.2\%) C. jejuni and (1.6\%) C. coli and liver (1.6\%) C.jejuni and $(1.6 \%) C$. coli. Susceptibilities of the recovered Campylobacter jejuni and $C$.coli, isolates to fifteen antibiotic discs clarified that gentamycin, neomycin, chloramphenicol and nalidixic acid in addition most of the strain were resistant to penicillin, ampicillin, tetracycline, sulfa methoxazole, trimethoprim, cephalothin and enerofloxacin . Public health hazard of enteropathogenic campylobacter was discussed and suggestive measures for reduction of campylobacter in broiler chicken farms were explained.
\end{abstract}

The genus campylobacter derived its name from the Greek word for "Curved rod" due to the curved, spiral or S-shaped morphology of these bacteria (Jordan et al., 2001). Campylobacter is Gram negative slender, curved, motile rod and non- haemolytic on blood media. It is a microaerophilic organism, which means it has a requirement for reduced level of oxygen. (Requires 5\% oxygen, $10 \%$ carbon dioxide and $85 \%$ nitrogen) for optimal growth. It is relatively fragile and sensitive to environmental stresses e.g $21 \% \mathrm{O}_{2}$, heating, drying, disinfectants and acidic conditions (Baron et al., 1994).

Campylobacteriosis is a contagious disease infected poultry characterized by low mortality and high morbidity with a chronic course (Peckham, 1984). Poultry serve as primary reservoir hosts of thermophilic Campylobacters. Up to $90 \%$ of broilers may be infected, while $100 \%$ of turkeys and $88 \%$ of domestic ducks may harbour the organisms (Calnek et al., 1997). Other than domestic birds, 36\% of Japanese quail (Ibrahim et al., 2005) and 78\% of young ostriches up to 8 weeks were infected (Stephens et al., 1998). Large numbers of Campylobacter's can be present as commonsal in the avian intestinal tract without any apparent gross lesions where the prevalence of infection in broiler breeder flocks has been found to be as hight as $80 \%$ (Evans, 1992).

Campylobacter has been associated with gastro-enteritis in human of all ages (Skirrow, 1977). Campylobacter enteritis is caused by the two closely related species, Campylobacter jejuni and Campylobacter coli (Skirrow, 1991). Campylobacter jejuni is a common and important cause of bacterial diarrhea in humans; equaling or exceeding salmonella and shigella spp.; In prevalence ; While, Campylobacter coli is less frequent than Campylobacter jejuni as a cause of diarrheic disease in humans (Acha and Szyfers, 1991).

Birds have been implicated as a source for these infections in human beings (Grant et al., 1980; Stern et al., 1985). Infection can be transmitted from chicken carcases and other products either transferred from hands to mouth by inexperienced food handlers. Consumption of raw or under cooked poultry meat or other innocent foods which may become cross contaminated from the raw products by means of hands and utensils, propably considered as the most frequent mode of infection (Kapperud et al., 1992).

The pathogenic mechanisms by which Campylobacter cause diarrhea in humans seem 
to be adhesion of the mucous membrane, toxin production and/or invasion of the epithelial cells, since the clinical effect varies between watery diarrhea and bloody diarrhea (Lindblom and Kaijser, 1995). The clinical manifestation of Campylobacter enteritis in human is an acute diarrhoeal illness often with acute abdominal cramping and fever. Other symptoms often present are nausea, headache and muscle pain. The illness usually occurs 2-5 days after ingestion of contaminated food (Blaser, 1997).

Recently the use of antibiotics in feed animal additives particularly in poultry farms has become of great concern for public health, because this practice may promote the emergence of multi- antibiotic resistant mutant of campylobacter species that can be transmitted to humans which are resistant to related human antimicrobial agents leading to difficulties in successfully treatment (Shakespeare, 2002).

The present study was planned to investigate the prevalence of enteropathogenic Campylobacter species in broiler chicken farms in different cities in El-Minia Governorate. In addition, bacteriological identification of isolated campylobacter species. Public health hazards of isolated antibiotic resistant campylobacter species, as well as antibiotic sensitivity patterns were intended to be estimated in vitro.

\section{Materials and methods}

Sampling. A total of 381 samples from different broiler chicken private farms located in different cities in El-Minia Governorate were employed during the winter 2008-2009. These were consisted of 216 freshly dead and 165 diseased and slaughtered broiler chickens aged 4-6 weeks. Samples were collected from jejunum, 2 caeci and liver separately from examined birds. Samples were directly transported to the laboratory in ice container within few hours for bacteriological procedures.

Preparation of samples. Small pieces from liver were crushed with one $\mathrm{ml}$ of sterile normal saline then thoroughly mixed in a sterile mortar. Also, one gram of faecal and gut fluid or mucous from caecal and intestinal contents were dissolved in one $\mathrm{ml}$ sterile normal saline. Centrifugation of the mixture at 1000 r.p.m for $5 \mathrm{~min}$. was applied. Enrichment procedure. Few drops of the supernatant were aspirated by sterile Pasteur pipette and cultured in semisolid thioglycolate broth in a small screw capped tube and incubated aerobically at $25^{\circ} \mathrm{C}-37^{\circ} \mathrm{C}$ and $42^{\circ} \mathrm{C}$ for $48-72$ $\mathrm{h}$.

Isolation technique. Two $\mathrm{ml}$ of the positive samples showing characteristic corkscrew motion under phase contrast microscope were aspirated by sterile Pasteur pipette and streaked onto the surface of Blaser's medium (Campy BAP) containing brucella agar base, 10\% defibrinated ovine blood and campylobacter selective supplement (skirrow, SR 69E, Oxoid) contained vancomycin 5mg, polymixin - B 1250 I $\mathrm{U}$ and trimethoprim $2.5 \mathrm{mg}$, was added as one vial for $500 \mathrm{ml}$ prepared medium. All inoculated plates were incubated for $48-72 \mathrm{~h}$ at $25^{\circ} \mathrm{C}$, $37^{\circ} \mathrm{C}$ and $42^{\circ} \mathrm{C}$ in gas pack system under microaerophilic conditions using campylobacter gas generating kits (Oxoid, BR38) producing $5 \%$ Oxygen , $10 \% \mathrm{CO} 2$ and $85 \%$ nitrogen.

Morphological and biochemical Identification. The suspected colonies were stained by modified Gram stain (with $0.8 \%$ solution of basic carbol fuchsin instead of safranine) to detect the morphology, and then examined under the phase contrast microscope to detect the darting motility. Suspected colonies were also subjected to biochemically identified according to (Holt et al., 1994).

Sodium Hippurate hydrolysis test. Colonies from Muller Hinton blood agar culture was inoculated into $0.5 \mathrm{ml}$ of sterile sodium hippurate solution in a small screw capped tube. Tubes were incubated including an un-inoculated control, aerobically at $37^{\circ} \mathrm{C}$ for $3 \mathrm{~h}$ according to (Lior, 1984). Over layed with $0.2 \mathrm{ml}$ of nine, hydrin solution without mixing. Development of a deep purple colour within $5 \mathrm{~min}$. indicates a positive result while development of a slight bluish colour regarded as negative results.

In-vitro anti- biogram sensitivity testing. The technique was carried out using the disc diffusion method according to Bopp et al., (1985). Campylobacter isolates (15 from each) were tested for resistance using gradient disk diffusion MIC to : naldixic acid $(30 \mu \mathrm{g})$, cephalothin $(30 \mu \mathrm{g})$ penicillin (10 IU), ampicillin $(10 \mu \mathrm{g})$, streptomycin $(10 \mu \mathrm{g})$, neomycin (30 $\mu \mathrm{g})$, gentamycin $(10 \mu \mathrm{g})$ erythromycin $(15 \mu \mathrm{g})$, chloramphenicol $(30 \mu \mathrm{g})$, nitrofuranation $(300$ $\mu \mathrm{g})$, tetracycline $(30 \mu \mathrm{g})$, oxytetracycline (30 $\mu \mathrm{g})$, trimethoprim $(1.25 \mu \mathrm{g})$ sulfamethoxazole $(25 \mu \mathrm{g})$, enerofloxacin $(10 \mu \mathrm{g})$. A swab of campylobacter isolates were inoculated into screw capped tubes containing $5 \mathrm{~mL}$ Muller Hinton broth (Dfco) then incubated for overnight at $37^{\circ} \mathrm{C}$. The turbidity was adjusted to match that of the standard Mcfarland 0.5 barium sulfate tube by adding sterile saline solution. From suspension few drops were evenly spread on 15 
$\mathrm{ml}$ Muller-Hinton agar plates supplemented with $5 \%$ defibrinated ovine blood, Inoculated plate was left for approximately half an hour and immediately after plate become dried, antibiotic discs were placed on the surface of agar plate by using discs dispenser (Oxoid). The plates were incubated for 72 hours at $37^{\circ} \mathrm{C}$ under the microaerophilic conditions and the diameter of the inhibitory zone for each disc was scored as described in the Oxoid manual.

\section{Results}

In this study, usually diseased chickens were showing clinical signs of depression, diarrhea and pasty vent plumage. Gross lesions revealed the distension from the jujunal region to the two caeci with accumulation of mucus and watery fluid. Haemorrhages were present in some cases. Incidence of Campylobacter jejuni and Campylobacter coli isolated from examined broiler chicken farms at different cities in ElMinia Governorate were illustrated in (Table 1). Detection of Campylobacter jejuni and Campylobacter coli from recently dead and diseased and slaughter broiler chickens were recorded in (Table 2). Existence of Campylobacter jejuni and Campylobacter coli recovered from different sites of the examined freshly dead and diseased slaughter broiler chickens were showed in (Table 3). Occurrence of Campylobacter species recovered from different sites of the examined broiler chickens were explained in (Table 4). Results of antimicrobial sensitivity tests of campylobacter species isolated from broiler chickens in vitro were represented in (Table 5).

\section{Discussion}

Campylobacteriosis is acute or chronic infection of humans caused food borne infection particularly in food of poultry origin. The infection in man manifested by acute enteritis, abdominal pain and diarrhea in most cases stool contain blood, pus or mucous, fever up to $40^{\circ} \mathrm{C}$ and sometimes vomiting. Abdominal signs may lead to laparotomy or appendectomy (Acha and Szyfers, 1991; Shakespeare, 2002; Hartmut et al., 2003). However, extra intestinal disease, including meningitis, endocarditis, septic arthritis and proctocolitis, is being increasingly recognized during the past few years, particularly in patients with acquired immuno deficiency syndrome (AIDS).(Koneman et al., 1992; Baron et al., 1994).

Campylobacters are fragile, fastidious and slow growing micro-organisms (Jordan et al., 2001). The recovery of campylobacter microorganisms is greatly influenced by oxygen content of the gaseous atmosphere in contact with solid isolated media. It is sensitive to air, surviving only one to two days on solid enrichment isolation media, two to four days in liquid media, and ten to twenty days in semisolid media at $25^{\circ} \mathrm{C}$ and survival can be enhanced by holding cultures at $4^{\circ} \mathrm{C}$ and by reducing oxygen tension (Park et al., 1984). These fact acts as the main failure that encountered with the laboratory technician that working in the identification of the isolated campylobacter microorganisms. Appropriate methods of transport and storage of campylobacters are necessary because these organisms are sensitive to desiccation. An enriched semi-solid brucella medium incorporating $10 \%$ ovine blood can be used to maintain viability of cultures for transport at $25^{\circ} \mathrm{C}$ for up to 3 weeks (Wang et al., 1980).

It is clear that campylobacter microorganisms are widely spread in broiler farms as mentioned by both (Jacobs-Reitsma et al., 1994; and Wieliczko, 1995). The chickens can be infected by campylobacter micro-organisms at 46 weeks of age. It is obvious from this study that campylobacter micro-organisms are widely infected in broiler farms distributed in different cities in El-Minia Governorate. It is clear from data illustrated in (Table 1) that the high rate of campylobacter species isolation showed, $23.8 \%$, $23.5 \%$ and $22.6 \%$ from Maggagha, Beni-Mazar and Samalout; respectively. On the other hand, low rate of detection, $21.3 \%, 15.8 \%$ and $12.1 \%$ from Abou-Curcas, Mallawey and Deer-Mouase, respectively. These findings mainly attributed to that El-Minia is a longitudinal Governorate. However, the distance between the east and west deserts become narrow toward the south where the weather is greatly differed from the north to the south.

The detection of Campylobacter jejuni and Campylobacter coli from recently dead and diseased slaughter broiler chickens (Table 2). Campylobacter species was mainly isolated from recently dead broiler chickens, 50 isolates with an incidence of $23.1 \%$ were recovered from 216 
Table (1): Incidence of Campylobacter jejuni and Campylobacter coli isolated from broiler chicken farms at different cities in El-Minia Governorate.

\begin{tabular}{lccccccc}
\hline \multirow{2}{*}{ Name of city } & \multirow{2}{*}{ No. of samples } & \multicolumn{2}{c}{$\boldsymbol{C}$. jejuni } & \multicolumn{2}{c}{$\boldsymbol{C}$. coli } & \multicolumn{2}{c}{ Total isolates } \\
\cline { 3 - 8 } & & No. & \% & No. & \% & No. & \% \\
\hline Maggagha & 42 & 8 & 19.0 & 2 & 4.8 & 10 & 23.8 \\
Beni- Mazar & 81 & 14 & 17.3 & 5 & 6.2 & 19 & 23.5 \\
Samalout & 93 & 17 & 18.3 & 4 & 4.3 & 21 & 22.6 \\
Abou- curcas & 75 & 11 & 14.7 & 5 & 6.7 & 16 & 21.3 \\
Mallawey & 57 & 7 & 12.3 & 2 & 3.5 & 9 & 15.8 \\
Deer- Mouase & 33 & 4 & 12.1 & 0 & 0.0 & 4 & 12.1 \\
Total & 381 & 61 & 16.0 & 18 & 4.7 & 79 & 20.7 \\
\hline
\end{tabular}

Table (2): Detection of Campylobacter jejuni and Campylobacter coli from freshly dead and diseased slaughter broiler chickens.

\begin{tabular}{|c|c|c|c|c|c|c|c|}
\hline \multirow[t]{2}{*}{ Source of samples } & \multirow{2}{*}{$\begin{array}{c}\text { No. of } \\
\text { samples }\end{array}$} & \multicolumn{2}{|c|}{ C. jejuni } & \multicolumn{2}{|c|}{ C. coli } & \multicolumn{2}{|c|}{ Total isolates } \\
\hline & & No. & $\%$ & No. & $\%$ & No. & $\%$ \\
\hline Freshly dead & 216 & 39 & 18.0 & 11 & 5.1 & 50 & 23.1 \\
\hline Diseased and slaughter & 165 & 22 & 13.3 & 7 & 4.2 & 29 & 17.6 \\
\hline Total & 381 & 61 & 16.0 & 18 & 4.7 & 79 & 20.7 \\
\hline
\end{tabular}

Table (3): Existence of Campylobacter jejuni and Campylobacter coli recovered from different sites of the examined freshly dead and diseased slaughter broiler chickens.

\begin{tabular}{|c|c|c|c|c|c|c|c|c|}
\hline \multirow[t]{2}{*}{ Source of samples } & \multirow[t]{2}{*}{ No. of samples } & \multirow[t]{2}{*}{ Recovery sites } & \multicolumn{2}{|c|}{ C. jejuni } & \multicolumn{2}{|c|}{ C. coli } & \multicolumn{2}{|c|}{ Total isolates } \\
\hline & & & No. & $\%$ & No. & $\%$ & No. & $\%$ \\
\hline \multirow{4}{*}{ Dead } & & Jejunum & 9 & 4.2 & 4 & 1.9 & 13 & 6.0 \\
\hline & 216 & Cecal contents & 28 & 13.0 & 6 & 2.8 & 32 & 14.8 \\
\hline & & Liver & 2 & 0.9 & 1 & 0.5 & 3 & 1.4 \\
\hline & & Jejunum & 7 & 4.2 & 2 & 1.2 & 9 & 5.5 \\
\hline \multirow[t]{2}{*}{ Diseased } & 165 & Cecal contents & 15 & 9.1 & 4 & 2.4 & 21 & 12.7 \\
\hline & & Liver & 0 & 0.0 & 1 & 0.6 & 1 & 0.6 \\
\hline Total & 381 & & 61 & 16.0 & 18 & 4.7 & 79 & 20.7 \\
\hline
\end{tabular}

Table (4): Occurrence of Campylobacter jejuni and Campylobacter coli recovered from different sites of the examined broiler chickens.

\begin{tabular}{lcccccc}
\hline \multirow{2}{*}{ Recovery sites } & \multicolumn{2}{c}{ Total isolates } & \multicolumn{2}{c}{ C. jejuni } & \multicolumn{2}{c}{. coli } \\
\cline { 2 - 7 } & No. & \% & No. & \% & No. & \% \\
\hline Jejunum & 22 & 5.8 & 16 & 4.2 & 6 & 1.6 \\
Cecal contents & 53 & 13.9 & 22 & 11.3 & 10 & 2.6 \\
Liver & 4 & 1.0 & 2 & 0.5 & 2 & 0.5 \\
Total & 79 & 20.7 & 61 & 16.0 & 18 & 4.7 \\
\hline
\end{tabular}

Table (5): Anti-microbial sensitivity tests of Campylobacter jejuni and Campylobacter coli isolated from broiler chickens in vitro.

\begin{tabular}{lccc}
\hline Antimicrobial disc & Disc potency & C. jejuni & C. coli \\
\hline Naldixic acid & $30 \mu \mathrm{g}$ & $\mathrm{S}$ & $\mathrm{S}$ \\
Neomycin & $30 \mu \mathrm{g}$ & $\mathrm{S}$ & $\mathrm{S}$ \\
Gentamycin & $10 \mu \mathrm{g}$ & $\mathrm{S}$ & $\mathrm{S}$ \\
Chloramphenicol & $30 \mu \mathrm{g}$ & $\mathrm{S}$ & $\mathrm{S}$ \\
Enerofloxacin & $10 \mu \mathrm{g}$ & $\mathrm{R}$ & $\mathrm{R}$ \\
Oxytetracyclin & $30 \mu \mathrm{g}$ & $\mathrm{M}$ & $\mathrm{M}$ \\
Erythromycin & $15 \mu \mathrm{g}$ & $\mathrm{M}$ & $\mathrm{R}$ \\
Nitrofuranation & $300 \mu \mathrm{g}$ & $\mathrm{M}$ & $\mathrm{R}$ \\
Streptomycin & $10 \mu \mathrm{g}$ & $\mathrm{M}$ & $\mathrm{R}$ \\
Sulfamethoxazole & $25 \mu \mathrm{g}$ & $\mathrm{R}$ & $\mathrm{R}$ \\
Trimethoprim & $1.25 \mu \mathrm{g}$ & $\mathrm{R}$ & $\mathrm{R}$ \\
Penicillin & $10 \mathrm{I} \mathrm{U}$ & $\mathrm{R}$ & $\mathrm{R}$ \\
Ampicillin & $10 \mu \mathrm{g}$ & $\mathrm{R}$ & $\mathrm{R}$ \\
Tetracycline & $30 \mu \mathrm{g}$ & $\mathrm{R}$ & $\mathrm{R}$ \\
Cephalothin & $30 \mu \mathrm{g}$ & $\mathrm{R}$ & $\mathrm{R}$ \\
\hline
\end{tabular}

$\mathrm{S}=$ Sensitive $(+++) \quad \mathrm{M}=$ moderate $(++) \quad \mathrm{R}=$ Resistant $(-)$

In vitro drug sensitivity test proved that all tested isolates were sensitive to Naldixic acid, Neomycin, Gentamycin and 
chicken carcases. While, the recovery rate from 165 diseased slaughter broiler chickens was $17.6 \%$ (29 isolates). Campylobacter infection consider as one of the most important agent that responsible for increase in daily mortality rate in broiler chicken farms. Mortality of $32 \%$ in infected chicks by Campylobacter jejuni was recorded by (Ruiz-palacios et al., 1981).

The existence of Campylobacter jejuni and Campylobacter coli recovered from different sites of the examined recently dead and diseased slaughter broiler chickens (Table 3). Campylobacter jejuni has been recovered from jejunum, caecal contents and liver with a rate of $4.2 \%, 13.0 \%$ and $0.9 \%$, respectively in recently dead broiler chickens. While, it was recovered from jejunum, caecal contents and liver with a rate of $4.2 \%, 9.1 \%$ and $0.0 \%$, respectively in diseased slaughter broiler chickens.

Campylobacter coli was isolated from recently dead broiler chickens with a rate of $1.9 \%, 2.8 \%$ and $0.5 \%$ from jejunum, caecal contents and liver, respectively. While, it was revealed from diseased slaughter broiler chickens with a rate of $1.2 \%, 2.4 \%$ and $0.6 \%$ from jejunum, caecal contents and liver, respectively. The high isolation rate of campylobacter species from caecal contents become in a greement with (Sayed and Mohamed, 2004; Fadel and Hamed, 2006). Generally, the principle niche for colonization in the bird is the caecum and caecal contents are the diagnostic sample of choice (Jordan et al., 2001). On the other hand, high isolation rate of campylobacter species from jejunum is recorded by (El-Seedy et al., 2008). The occurrence of Campylobacter jejuni and Campylobacter coli recovered from different sites of the examined broiler chickens. Table 4 showed that Campylobacter jejuni was recovered from broiler carcases with a rate of $(16.0 \%)$. Several authors comes in agreement with this result, Fernandez and Torres, (2000), (19.7\%), Sayed, (2000), (19.2\%) and Sayed and Mohamed, (2004), (16.7\%)). High prevalence rates of Campylobacter jejuni were detected in broilers, $(43.0 \%), \quad(53.7 \%), \quad(39.6 \%), \quad(73.2 \%) \quad$ and $(52.6 \%)$ reported by, Atanassova and Ring, (1999); Chou and Tsai, (2001); Wedderkopp et al. (2001); Saleha, (2002); El-Seedy et al. (2008), respectively. Campylobacter coli was isolated also from broiler carcases with a rate of (4.7\%).Several authors come in agreement with the present result, (Fernandez and Torres, (2000), (6\%) and Wedderkopp et al . (2001),
$(5 \%))$. On the other hand, high rates of detection (28.3\%), (13\%), (26.8\%) and (42.3\%) were estimated by (Saleha et al., 1996; Atanassova and Ring, 1999; Saleha, 2002; El-Seedy et al., 2008).

The obtained results in Table (5) demonstrated the most effective antibiotics for all isolates (15 from each) in vitro were Gentamycin, Neomycin, chloramphenicol and Naldixic acid. Some similarities with these results as reported by Morris and Patton, (1985); Moffok and Leberes, (1992); Rabie, (1992); Das et al., (1996); Abd EL-Moneim, (1998); Fadel and Hamed, (2006). On the other hand, most isolates of campylobacter species were resistant to penicillin, ampicillin, tetracycline, sulfamethoxazole, trimethoprim, cephalothin and enerofloxacin while oxytetracycline revealed moderate effective for most campylobacter isolates. These results are agreed with those reported by Erdger and Diker, (1995); Sayed, (2000). While disagreed with those, reported by (Salem et al., 1986; Rabie, 1992; Sayed and Mohamed, 2004) as they mentioned that oxytetracycline and tetracycline were highly sensitive.

The high antibiotic resistance rates detected could be due to the wide spread use of antibiotics in broiler chickens, particularly in feed as feed additives as well as due to being use indiscriminately, (Saleh, 2002). In addition, Campylobacter is one of the micro-organisms of moderate intrinsic susceptibility which require only one mutation to become resistant (Wiedemann and Heisig, 1994). Also, resistance to Fluoroquinolones as enerofloxacin appears to develop very rapidly and the incidence of resistant isolates has increased in humans in recent years which have coincided with the approval of these drugs for veterinary use. Consequently the use of these antibiotics in animal production systems may have serious implications for the treatment of human infections (Jordan et al., 2001).

As shown in Table (5) Campylobacter coli can be differentiated from Campylobacter jejuni by the hippurate hydrolysis test since, Campylobacter jejuni are the only Campylobacters that hydrolyze hippurate (Koneman et al., 1992).

In conclusion, Campylobacter infection in broiler chicken farms as general causing enteritis manifested by diarrhea, hence during missfield diagnosis may be passed as one of common enteric diseases like, Colibacillosis, 
Salmonellosis, Coccidiosis and/or clostridial infection and so miss-treatment failure occurs. Also, the high isolation rate of campylobacter spp. in broilers showing chronic respiratory disease (CRD) as a concurrent infection may be attributed to the associated decreased immunity (Fedel and Hamed, 2006). For these reasons, Campylobacteriosis should be correctly diagnosed by laboratory investigation as one of the most important avian pathogens for its public health hazard. Moreover, infected broiler chicken by campylobacter species act as a main reservoir of infection to other domestic farm animals and human beings.

\section{References}

Abd EL-Moneim, E. M. (1998): Occurrence of food poisoning organisms in poultry product with special reference to campylobacter. Ph. D. Thesis, Fac. Vet. Med . Zagazig Univ ., Egypt.

Acha, P. N. and Szyfers, B. (1991): Zoonoses and Communicable Diseases Common to Man and Animals $2^{\text {nd }}$ Ed. Pan American Health organization, Washington D.C.

Atanassova, V. and Ring, C. (1999): Prevalence of Campylobacter spp . in poultry and poultry meat in Germany . Int . J. Food Microbiol., 51:187-190.

Baron, E. J.; Peterson , L. R. and Finegold, S. M. (1994): Bailey and scott's . Diagnostic Microbiology. $9^{\text {th }}$ Ed. Mosby.Centers for Disease Control. 1988. Campylobacter Isolates in the United States.

Blaser, M. J. (1997): Epidemiologic and clinical features of Campylobacter jejuni infections . J. infect. Dis ., 176 : 103-105.

Bopp, F. L.;Bikness, K. A.; Washsmuth, I. K. and Barrett, T. J. (1985): In vitro antimicrobial susceptibility , plasmid analysis and serology of epidemic Campylobacter jejuni . J. Clin. Microbiol., $21: 4-7$.

Calnek, B. W.; Barnes, H. J.; Beard, C. W.; Mc Dougald, L.R. and Saif, Y. M. (1997): Diseases of poultry. $10^{\text {th }}$ Ed. Mosby-Wolfe . Iowa State Univ . press., USA .

Chou, J. and Tsai, H. (2001) : Prevalence and antimicrobial susceptibility of salmonella and Campylobacter from meat-type chickens in Taiwan. J. Chin. Soc. Vet . Sci ., $27:$ 27-38.

Das, S. C.; Mullick, S. G. and Biswas, G. (1996): Isolation and Identification of campylobacter from poultry: biotyping and in vitro-antimicrobial sensitivity. Ind. J. Vet. Res., 5: 29-34.

EL-Seedy, F. R.; Radwan, I. A.; Abdalla, M. M. and Tolba, N. F. (2008): Prevalence and pathogenicity of campylobacter species in chickens in El-Fayoum Governorate . Assiut Vet. Med. J., 54: 366-379.

Erdger, J. and Diker, K. S. (1995): Multiple antibiotic resistance in poultry isolates of campylobacter . Veterinar fak Ltesi Dergisi, Ankara universitesi, Ankara, Turkey .

Evans, S. J. (1992): Introduction and spread of thermophilic campylobacters in broiler flocks. Vet. Rec., 131: 574-576.

Fadel, H. M. and Hamed, D. M. (2006): Studies on the prevalence pathogenicity and significance of campylobacteriosis in poultry. $12^{\text {th }}$ Sci. Cong., Fac. Vet. Med., Assiut univ., Egypt . pp 477-491.

Fernandez, H. and Torres, N. (2000): Occurrence of Campylobacter jejuni and Campylobacter coli in three groups of hens of different geographic origin in southern Chile . Arch. Med. Vet., 32: 241-244.

Grant, I. H.; Richardson, N. J. and Bokkenheust, V. D. (1980): Broiler chickens as potential source of campylobacter infections in humans . J. Clin. Microbiol., 11: 508-510.

Hartmut, K.; Albert, W.; Max, A.; Burkhard, E.; Henry, D.; Hans Gerd, S.; Werner, S.; Alexander, V. and Horst, S. (2003): Zoonoses, infectious diseases transmissible from animals to humans $.3^{\text {rd }}$ ed. American Society for Microbiology, Washington D.C.

Holt, J. H.; Krieg, N. R. and Sneatn, P. H. A. (1994): Bergey's Manual of Determinative Bacteriology. $9^{\text {th }}$ Ed.

Ibrahim, R. S.; Hassanein, R. and Moustafa, F. A. (2005): Campylobacter jejuni infection in Japanese Quail (Coturnix Coturnix) " isolation, pathogenicity and public health implications. Assiut Vet. Med. J., 51 : 212-226.

Jacobs-Reitsma, W. F.; Giessen, A. W. Van De; Bolder, N. M. and Mulder, R. W. (1995): Epidemiology of Campylobacter spp. at two Dutch broiler farms. Epidemiol. Infec., 114 : 413-421.

Jordan, F.; Pattison, M.; Alexander, D. and faragher, T. (2001): Poultry Diseases $5^{\text {th }}$ ed. W.B. Saunders . London.

Kapperud, G.; Skjerve, E.; Bean, N.; Osroff, S. M. and lassen, J. (1992): Risk factors for sporadic campylobacter infections : results of case control study in southern Norway. J. Clinic. Microbiol., 30:3117-3121.

Koneman, E. W.; Allen, S. D.; Janda, W. M.; Schreckenberger, P. C. and Winn, W. C. (1992): Color Atlas and Textbook of Diagnostic Microbiology, $4^{\text {th }}$ ed., J.B. Lippincott Company Philadelphia.

Lior, H. (1984): New extended biotyping scheme for Campylobacter jejuni, Campylobacter coli and Campylobacter laridis. J. Clin. Microbiol., 20:636-640.

Lindblom, G. B. and Kaijser, B. (1995): In vitro studies of Campylobacter jejuni / coli strains from hens and humans regarding adherence, invasiveness and Toxigenicity . Avian Dis., 39:718-722.

Moffok, F. and Leberes, E. (1992): Results of technique of isolation and identification of campylobacter in food. Arch-Inst. Pasteur Algerie, 58:239-246.

Morris, G. K. and Patton, C. M. (1985): Manual of Clinical Microbiology : Campylobacter $4^{\text {th }}$ Ed. American Society for Microbiology, Washington, D.C.

Park, C. E.; Smibert, R. M.; Blaser, M. J.; Vanderzant, C. and Stern, N. J. (1984): Campylobacter in "Compendium of Methods for the Microbiological Examination of Foods" $2^{\text {nd }}$ Ed. 366-404. Speck. M.L. (ed) American Public Health Association, Washington, D.C.

Peckham, M. C. (1984): Avian Vibrionic Hepatitis. In Hofstad, et al., (eds.) Diseases of Poultry, $8^{\text {th }}$ ed. Pp. 221231.Iowa State Univ. Press, Ames.

Rabie, N. (1992): Studies on campylobacteriosis in chickens. Ph. D. thesis, Fac. Vet. Med., Cairo Univ., Egypt. Ruiz-Palacios, G. M.; Escamilla, E. and Torres, N. (1981): Experimental Campylobacter diarrhea in chickens . Infect. Immun., 34:250-255.

Saleha, A. A. (2002): Isolation and characterization of Campylobacter jejuni from broiler chickens in Malaysia . Int. J. Poult. Sci., 1: 94-97.

Saleha, A. A.; Ibrahim, A. and Kamarzaman, A. (1996): Campylobacter in village chickens. Prevalence and biotypes. J.Vet. Malaysia, 8:25-27.

Salem, B.; Abd El Motelib, T. Y.; EL-Zanaty, K. and Nfady, A. A. (1986): A first record of an outbreak of vibrionic hepatitis in laying hens in Egypt. Assiut Vet. Med. J., 17: 231-237. 
Sayed, A. M. (2000): Campylobacter infection in broiler chickens in Assiut. Assiut Vet. Med. J., 42: 213-222.

Sayed, A. S. and Mohamed, A. A. (2004): Surveillance of enteropathogenic campylobacter in raw poultry meat and some poultry products in Assiut City. Assiut Vet. Med. J., 49: 80-94.

Shakespeare, M. (2002): Zoonoses Pharmaceutical press. New York. Pp. 248-250.

Skirrow, M.B. (1977): Campylobacter enteritis . A new disease. British Med. J., 2:9-11.

Skirrow, M.B. (1991): Epidemiology of Campylobacter enteritis . Int. J. Food Microbiol., 12:9-16.

Stephens, C. P.; On, S.L. and Gibson, J. A. (1998): An outbreak of infectious hepatitis in commercially reared ostriches associated with Campylobacter coli and Campylobacter jejuni. Vet. Microbiol., 61:183-190.

Stern, N. J.; Hernandez, M. P.; Blankenship, I.; Deibl, K. E.; Doores, S.; Doyle, M. P.; Ng, H.; Pierson, M. D.;
Sofos, N. J.; Sveum, W. H. and Westhoff, D. C. (1985): Prevalence and distribution of Campylobacter jejuni and Campylobacter coli in retail meats. J. Food Prot., 48:595599.

Wang, W. L. L.; Luechtefeld, N. W.; Reller, L. B. and Blaser, M. J. (1980): Enriched brucella medium for storage and transport of cultures of Campylobacter fetus subsp jejuni. J. Clin. Microbiol., 12:479-480.

Wedderkopp, A.; Gradel, K.; Jorgensen, J. and Madsen, M. (2001): Preharvest surveillance of campylobacter and salmonella in Danish broiler flocks: a 2 year study. Int. J. Food Microbiol., 68:53-59.

Wiedmann, B. and Heisig, C. (1994): Mechanisms of Quinolone resistance. Infection, 22:573-579.

Wieliczko, A. (1995): The role of campylobacter in poultry pathology. Part I Epidemiological studies on campylobacter infections in poultry. Medycyna Weterynaryine. 51: $150-$ 152.

\section{إصابة قطعان بداري التسمين بالكامبيلوباكتر في محافظة المنيا}

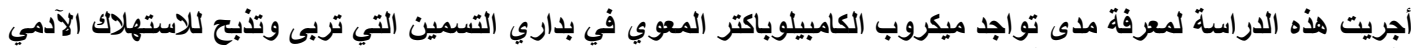

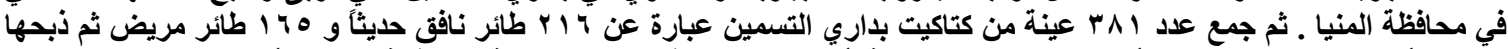

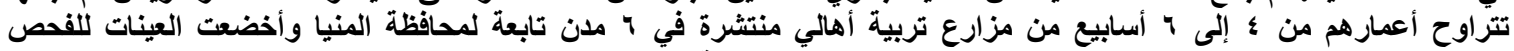

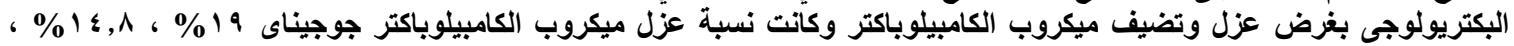

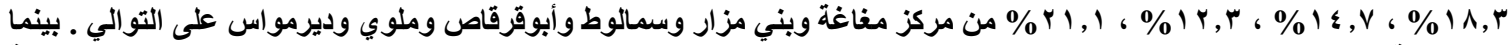

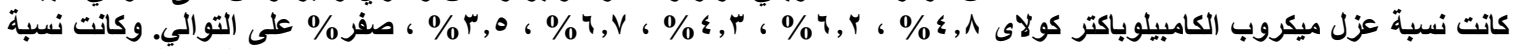

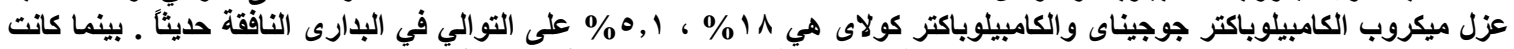

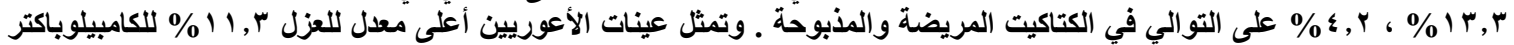

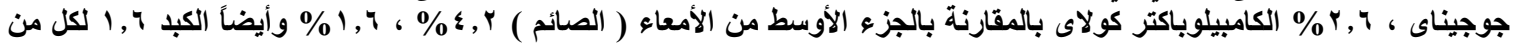

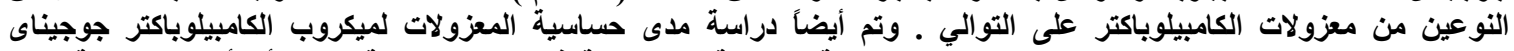

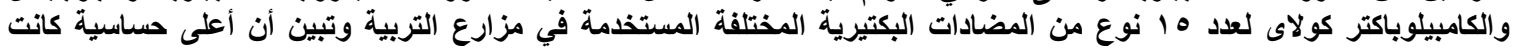

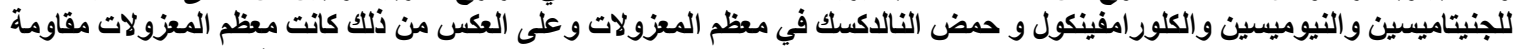

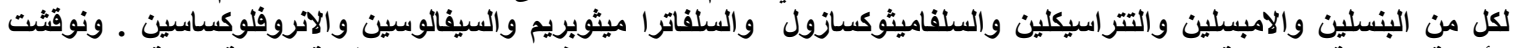

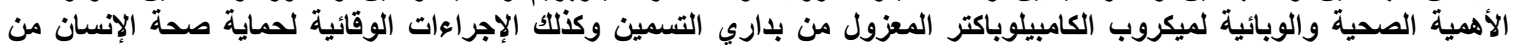

